\title{
Learning Process Effectiveness During the COVID-19 Pandemic: Teleproctoring Advanced Endoscopic Skills by Training Endoscopists in Endoscopic Sleeve Gastroplasty Procedure
}

\author{
Manoel Galvao Neto ${ }^{1} \cdot$ Jonathan Jerez ${ }^{2} \cdot$ Vitor Ottoboni Brunaldi ${ }^{3}$ (D) David Cabrera ${ }^{4} \cdot$ Christian Benavides $^{4}$. \\ Monica Moreno ${ }^{4} \cdot$ Ginesio Romero $^{4}$. Daniela Guiatara ${ }^{4} \cdot$ Barham K. Abu Dayyeh $^{5}$
}

Received: 9 August 2021 / Revised: 6 October 2021 / Accepted: 8 October 2021 / Published online: 18 October 2021

(c) The Author(s), under exclusive licence to Springer Science+Business Media, LLC, part of Springer Nature 2021

\begin{abstract}
Background and Aims The COVID-19 pandemic has led health institutions to cancel many of the activities including training in different fields. Most practices and training programs have been encouraged to use teleproctoring as an alternative method to enhance physician's ability and assure training. We aimed to evaluate remote training program for endoscopy sleeve gastroplasty (ESG).

Methods Ten consecutive patients underwent an endoscopic sleeve gastroplasty procedure guided by a proctor expert using an online platform. A stepwise approach was created to assure skill acquisition.

Results All cases were safely performed with no serious adverse events under teleproctoring. The average surgical and suturing times significantly decreased during the training model. From the first 5 cases to the last 5 ones, the endoscopic procedure time decreased from 120 to $93.4 \mathrm{~min}$ while suturing time from 92.8 to $68.4 \mathrm{~min}$. The effect size was large in both cases, and the changes were meaningful according to the fitted learning curves.

Conclusions The proposed teleproctoring program was effective to deliver advanced endoscopic skills such as endosuturing for ESG, despite the restrictions imposed by the COVID-19 pandemic.
\end{abstract}

Keywords Education · Training · Bariatric $\cdot$ Endoscopy $\cdot$ Gastric sleeve $\cdot$ Teleproctoring $\cdot$ COVID-19

\section{Key points}

- The COVID-19 pandemic has imposed several restrictions to in-person learning, and teleproctoring has risen as a suitable alternative.

- A telementee is capable of acquiring advanced endoscopic skills assessed through a learning curve model.

- The proposed teleproctoring stepwise approach to teach endoscopic sleeve gastroplasty is feasible and effective.

Vitor Ottoboni Brunaldi vobrunaldi@hcrp.usp.br

1 Division of Gastrointestinal Endoscopy, ABC Medical School, São Paulo, Brazil

2 Diagnostic and Therapeutic Gastroenterology Amazon Region, Puyo, Ecuador

3 Center for Digestive Endoscopy, Surgery and Anatomy Department, Hospital das Clínicas de Ribeirão Preto, Ribeirão Preto, Brazil

4 Endoscopic Bariatric, Overweight Obesity and Metabolism Clinic, Quito, Ecuador

5 Department of Gastroenterology and Hepatology, Mayo Clinic, Rochester, MN, USA

\section{Introduction}

Although bariatric procedures have solid outcomes in fighting obesity, complications such as leaks and weight regain may arise. In this sense, numerous patients refuse surgery but are receptive to less-invasive alternatives for weight loss. Bariatric endoscopy is a rising subspecialty that has altered the way of dealing with patients looking for nonsurgical bariatric treatments. It provides relevant, long-lasting weight loss and improves obesity-related comorbidities in a relevant percentage of subjects in short and midterm. It is particularly indicated for patients unfit for surgery, especially those with obesity grades I and II without associated comorbidities [1,2].

The endoscopic sleeve gastroplasty (ESG) is a minimally invasive procedure that reduces the size of the gastric chamber. It involves remodeling of the greater curvature of the stomach by applying endoscopic full-thickness suturing. The procedure can help individuals with obesity in promoting weight loss and improving some health conditions [3, 4]. 
Training in bariatric endoscopy (BE) and establishing a training program in bariatric endoscopy require dedication and commitment from various participating parties, mainly trainees and educators. Although developing technical endoscopic expertise is essential, training in bariatric endoscopy requires a substantial cognitive component that is best obtained through working in a multidisciplinary setting.

Traditionally, trainees learn how to perform endoscopy in a clinical setting under the supervision of an expert endoscopist. This teaching method benefits from on-thejob training and from receiving immediate feedback from the supervisor. Alternatively, teleproctoring has long been employed in surgical training and allows virtual real-time instructions through video and audio interaction from a distant location. In this sense, the proctor may train a fellow in a clinical environment $[5,6]$.

The COVID-19 pandemic and the following social distancing guidelines fostered technological innovations and training within medicine and medical education. As such, it also created a timely opportunity to employ teleproctoring in BE training. Despite on-site or teleproctoring, one should always consider the key elements for an adequate learning process: clear definition of the learning goals, appropriate assessment of those goals, assessment of and respect to the trainee's own learning pace, progress assessment, and controlled feedback [7].

Of note, there is no scientific literature regarding teleproctoring for the ESG to date. Thus, this is the first report to describe a teleproctoring training program to perform such endoscopic bariatric therapy.

\section{Methods}

One expert physician in bariatric endoscopy, whose abilities had been previously demonstrated, created a stepwise teleproctoring training program. A trainee, who was familiar with basic endoscopic therapeutic procedures (intragastric balloon, hemostasis techniques, endoscopic mucosal resection, etc.), received theoretical classes, practices, and tests for handling the device. The proctor implemented the training by remotely mentoring and evaluating the process through broadband connectivity, action cameras, video capture cards, tripods, smartphones, and Bluetooth earbuds. Internet connection was tested before each procedure and meeting to be at a minimum of $10 \mathrm{mbps}$ (megabites per seconds). Both proctor and trainee used wired connections but had $4 \mathrm{G}$ connections as a backup in case of connectivity issues during livestreaming. A web conferencing platform $\left(\right.$ Zoom $\left.{ }^{R}\right)$ was used for the training sessions and the cases as well. It allows users to directly interact via audio and video call. Along with 2 room webcams, the endoscopy tower video output was connected to a video capture card and from that to a computer linked to a Zoom meeting for broadcasting (Fig. 1). The trainee carried out the training process and the endoscopic procedures at a private clinic in Ecuador from March to August 2020, while the telementor was an expert from Brazil. All patients agreed to participate in this educational program and signed a written informed consent to undergo the ESG under this teleproctoring program. The project was approved by the local ethics committee.

\section{Description of teleproctoring training program}

The training project comprised at least 6 online meetings, as follows:
Fig. 1 Schematics of the endoscopy transmission
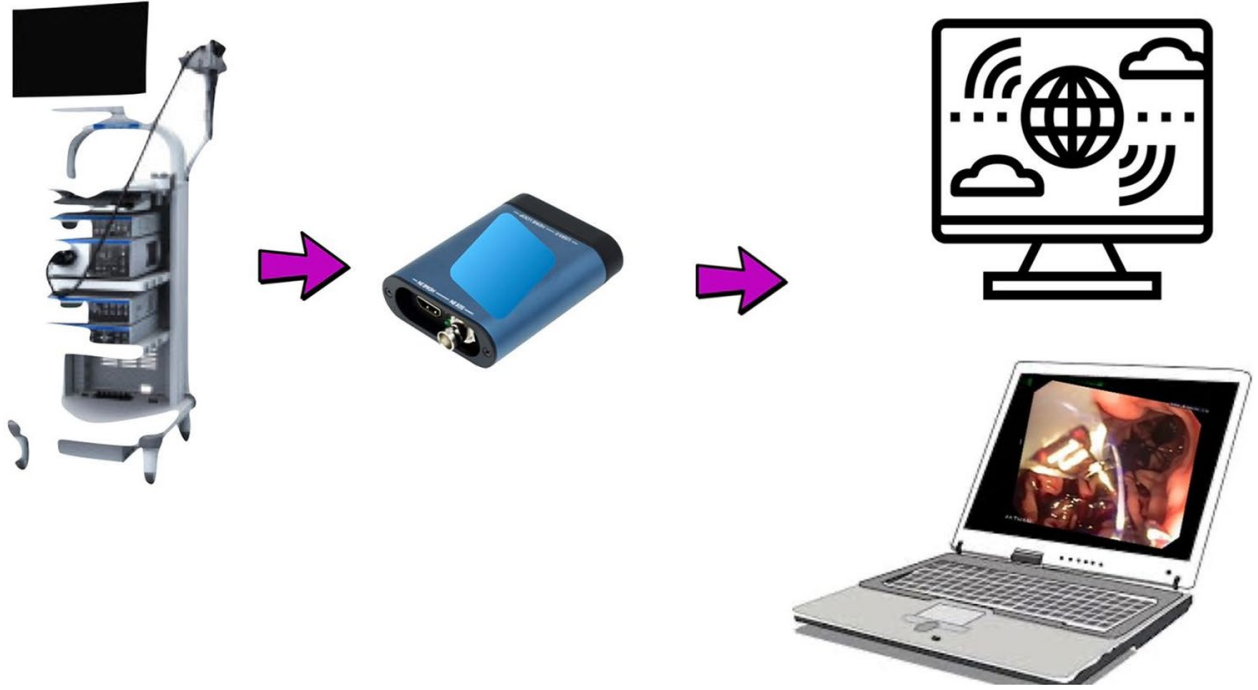
First meeting: understand the needs and establish the goals and present the current literature and didacts.

Second meeting: to define patient selection, pre- and postprocedural care protocols, alignment of language (Spanish), and tech wording.

Third meeting: broadcasting a procedure that the local team was already trained and comfortable with (intragastric balloon placement); this meeting also aimed at testing Internet status, room scenic, camera positioning, and communication (proctor to surgeon through wireless headphones).

Fourth meeting: to present and discuss eligible patients.

Fifth meeting: ex vivo hands-on lab training under teleproctoring guidance; during this step, the trainee got familiar with the equipment and suturing device; one porcine stomach was used to perform several sequential stitching until suturing maneuvers were fully understood; the stitching pattern followed the ESG principals, but the aim of this step was mainly acquisition of suturing motor skills; therefore, the trainee performed stitches until there was no remaining suturing sites in the stomach.

Sixth and following meetings: real human ESG cases under teleproctoring guidance.

\section{Theoretical component}

The proctor presented scientific literature and procedurerelated data for theoretical learning. Moreover, the trainee received video cases to get familiar with the relevant anatomy and steps of the procedure. Both mentor and student defined the theoretical learning goals at the first meeting. The following online encounter took place 3 months after the one, by the time the trainee had plenty theoretical knowledge concerning the proposed procedure.

\section{Practical component}

The proctor evaluated the trainee's endoscopic skills before initiating the specific training. From that on, the proctor accompanied the trainee during all learning and improvement process in real time. By video web meetings, live interactive demonstration of techniques and maneuvers were provided to the student. The proctor was able to follow the trainee's performance in real time, and they could communicate during the session to refine the technique.

\section{Patients' preparation}

Before the ESG procedure, patients must comply with several topics: office visit to an internist for preoperative evaluation; office visits to nutrition specialist, psychologist, and endocrinologist; and an elective upper digestive endoscopy. Patients underwent ESG under general anesthesia and the procedures were carried out on left lateral position and after administration of antibiotic prophylaxis.

\section{Technique}

The endoscopic sleeve gastroplasty (ESG) involves the placement of internal stitches to the stomach to reduce the volume and make it tubular. All procedures were performed in a private endoscopy clinic. For ESG, a double-channel gastroscope (Olympus CV160, Olympus Medical Systems Corp, Tokyo, Japan) and $\mathrm{CO} 2$ insufflation were employed. A specific esophageal overtube (Apollo Endosurgery, Austin, TX, USA) facilitated the passage of suturing device and minimized deflation as it carries a balloon cuff at its distal end. The Apollo Overstich ${ }^{\circledR}$ is an endoscopic suturing system that allows full-thickness tissue apposition using a curved needle and polypropylene $2-0$ threads. The first stitch was where the Incisura Angularis meets in the anterior wall and then following an imaginary straight line in the direction of the posterior passing through the greater curvature at an estimated distance of $2 \mathrm{~cm}$ from each stitch. Once the suture line reached the posterior wall, it should return to the anterior line in a similar fashion forming the "U" stitching pattern. On the following sutures, the same pattern was applied on the gastric body distal to proximal up to the proximal gastric fundus. The surgical procedure was performed according Galvao Neto et al.'s description [8] and clinical management according to the Brazilian Consensus on ESG [9].

\section{Statistical analysis}

Results were reported as mean \pm standard deviation (SD) for continuous data and as frequencies and proportions for categorical data. Groups were compared using Mann-Whitney $\mathrm{U}$ tests for non-parametric continuous variables. Cohen coefficient was used to assess the effect size. Values between 0.2 and 0.49 were interpreted as small effect, those between 0.5 and 0.79 as moderate effect and values greater than 0.8 as large effect. To define the "learning curve," nonlinear regression was used to fit an inverse curve, with case number as the independent variable and procedure time as the dependent variable. This statistical method yields an estimate of a (asymptote) and b (slope), as described by Feldman et al. [10]. Two values were derived from these estimates: "learning plateau," defined as the theoretical best score achievable (when $\mathrm{X}=$ infinity, $\mathrm{Y}=\mathrm{a}$ ) and the "learning rate," defined as the number of procedures required to reach $90 \%$ of potential $(\mathrm{Y}=0.9 \mathrm{a}$ when $\mathrm{X}=10 * \mathrm{~b} / \mathrm{a})$. The outcome measurements were length of procedure (LOP). The LOP was defined as time from initial endoscope entry into the mouth to final endoscope withdrawal. Data sets were compiled using Microsoft Excel, and all statistical analyses were performed using SPSS version 24 (SPSS Inc, Chicago, IL, USA). 


\section{Results}

During this training program, 10 adult patients were included, and all were successfully livestreamed in real time. Among those individuals, $60 \%$ were female and $40 \%$ were male. Patients were between 23 and 67 years old with a mean BMI of $37.7 \mathrm{~kg} / \mathrm{m}^{2}(30.2-43.5)$. There were two intraprocedural adverse events, namely, one hematoma and one bleeding. However, only one required intervention (endoscopic clipping). No serious adverse events (SAE) were recorded in the postoperative period. Table 1 summarizes the overall data from the procedures.

Mean duration of the endoscopic procedure and of the suturing suture were $106.4 \mathrm{~min}(75-142)$ and $80.9 \mathrm{~min}$ (57-115), respectively. The trainee experienced significant reductions in overall operative time during the first 10 cases $(p \leq 0.05)$. The effect sizes were 1.4 and 1.5, respectively, which represent a large responsiveness to change. Table 2 summarized learning data, and Figs. 2 and 3 demonstrate graphically the reduction in operative time.

Table 1 Overall data for the 10 endoscopic sleeve gastroplasty procedures

\begin{tabular}{ll}
\hline Gender & \\
\hline Female & $6(60 \%)$ \\
Male & $4(40 \%)$ \\
Age (years) & $46.9(23-67)$ \\
BMI $\left(\mathrm{kg} / \mathrm{m}^{2}\right)$ & $37.7(30.2-43.5)$ \\
Comorbidities & \\
Diabetes & $1 / 10(10 \%)$ \\
Hypertension & $4 / 10(40 \%)$ \\
Hypothiroidism & $4 / 10(40 \%)$ \\
Obstructive sleep apnea & $1 / 10(10 \%)$ \\
Dyslipidemia & $2 / 10(20 \%)$ \\
Adverse events (intra-operative) $(2 / 10)$ & \\
$\quad$ Hematoma-loss of a thread & 1 \\
$\quad$ Hemorrhage & 1 \\
Intervention & \\
$\quad$ Endoscopic clipping & 1 \\
\hline
\end{tabular}

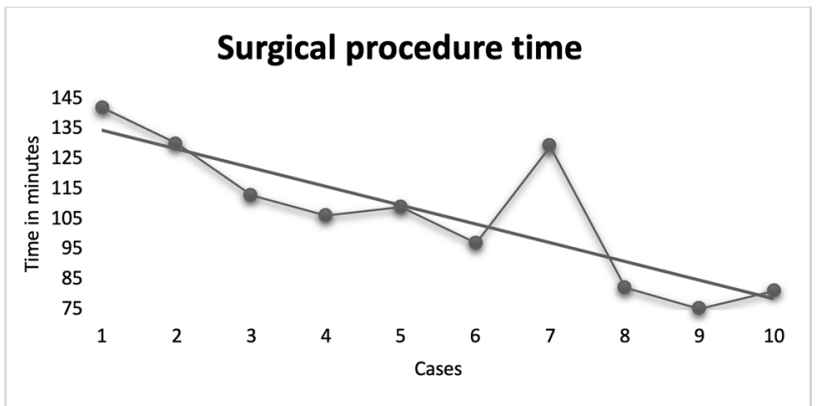

Fig. 2 Progress in the overall procedure duration. Dotted line: real values; Continue line: trend

The inverse curve was an acceptable fit for the performance curves (Fig. 4), with $\mathrm{r}^{2}=0.55$ and $\mathrm{r}^{2}=0.51$ for endoscopic procedure and suturing duration, respectively. That means that the reduction in time from the first to the last case was meaningful. The trainee became experienced after the fourth case (turning point) in both cases. Of note, case 7 was notably longer than other due to intraprocedural bleeding which was managed by endoscopic clipping.

No problems regarding broadcasting were detected and the videos had enough definition for the proctor to follow the cases and intervene. Figures $5 \mathrm{a}$ and $\mathrm{b}$ illustrate the transmission of the 9th case and reveals the satisfactory quality of the images.

During the training, the cameras projected clear realtime images of procedures. Figure 6 shows the four possible images and scenes in an ongoing teleproctored ESG, and Fig. 7 demonstrates the schematics for room setup.

\section{Discussion}

This study describes the first training program to perform an endoscopic sleeve gastroplasty (ESG) under teleproctoring guidance. Proctoring is considered a necessary step of a new skill acquisition. High band-width wireless technology allows bidirectional visual and audio communication with minimal loss to a recipient's ability to absorb key information.
Table 2 Comparison of means between first and last cases

\begin{tabular}{|c|c|c|c|c|c|c|}
\hline & \multicolumn{2}{|c|}{ First five cases } & \multicolumn{2}{|c|}{ Last five cases } & \multirow[t]{2}{*}{ Effect size } & \multirow[t]{2}{*}{$p$ value* } \\
\hline & Mean & SD & Mean & SD & & \\
\hline $\begin{array}{l}\text { Endoscopic pro- } \\
\text { cedure (min) }\end{array}$ & 120.0 & 15.4 & 92.8 & 21.7 & 1.4 & 0.05 \\
\hline $\begin{array}{l}\text { Suturing time } \\
\text { (min) }\end{array}$ & 93.4 & 17.1 & 68.4 & 14.1 & 1.5 & 0.05 \\
\hline
\end{tabular}

*Mann Whitney T test 


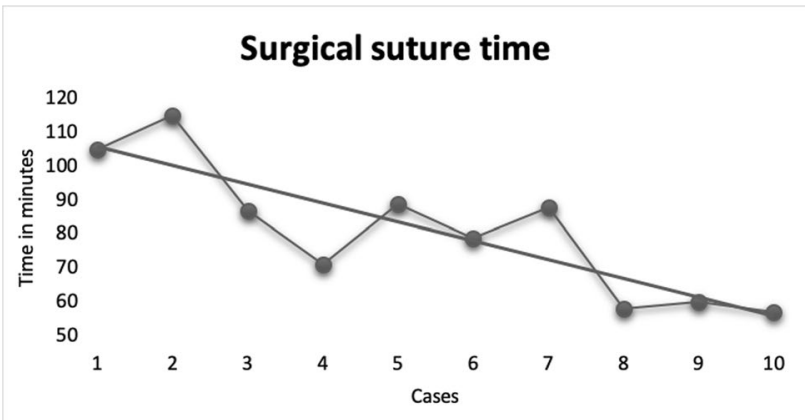

Fig. 3 Progress in the suturing duration. Dotted line: real values; Continue line: trend

Teleproctoring in surgery was first reported more than 20 years ago [5]. According to McCullough et al., it is a "technology where audio and video interaction facilitate the virtual presence of a teacher to provide real-time instruction and technical assistance from a different geographic location." Similar to the traditional approach, this method allows the proctor to provide training to the surgery fellow amid clinical setting [6]. However, it mitigates logistic obstacles concerning distance, time constraints, and costs [11]. Teleproctoring was a success as an educational tool in different countries $[6,12,13]$.

The combination of telecommunications and information systems into the operating room provides new opportunities for telemonitoring and teleproctoring, as knowledge is in a continuous state of growth [14]. However, the familiarization with telehealth must involve training future providers to use such technologies and providing this modality of care to patients [15].

In this report, the trainee learned how to perform an ESG proctored by an international expert who was unavailable for on-site mentoring due to the COVID-19 pandemic travel
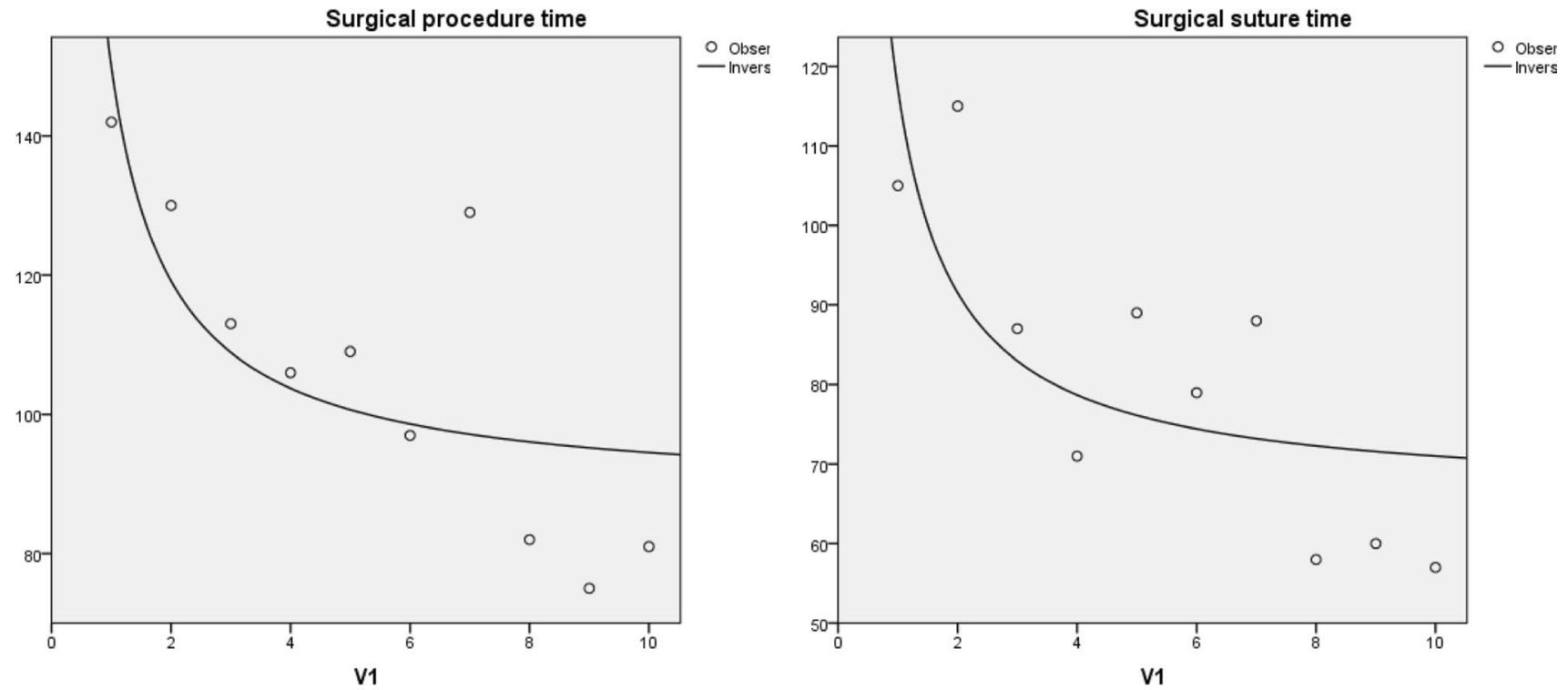

Fig. 4 Fitting inverse curve for learning performance

Fig. 5 Endoscopic aspect of the procedure. (a) First endoscopic suturing line. (b) Formation of the tubular stomach

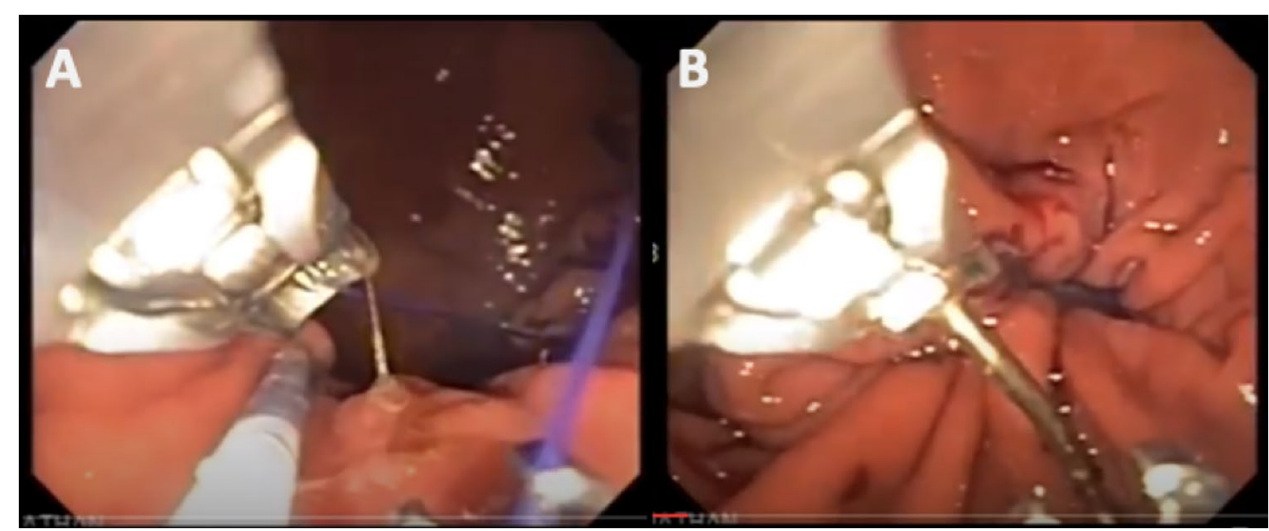


Fig. 6 Various aspects of an ongoing teleproctored procedure. (a) Endoscopic view, (b) teleproctor (trainee's view), (c) room view for body movements of the endoscopist and the team, (d) detail of the endoscopic body and equipment movements. Note. Written permission for publication was obtained from the identifiable individual (Dr. Manoel Galvao Neto)
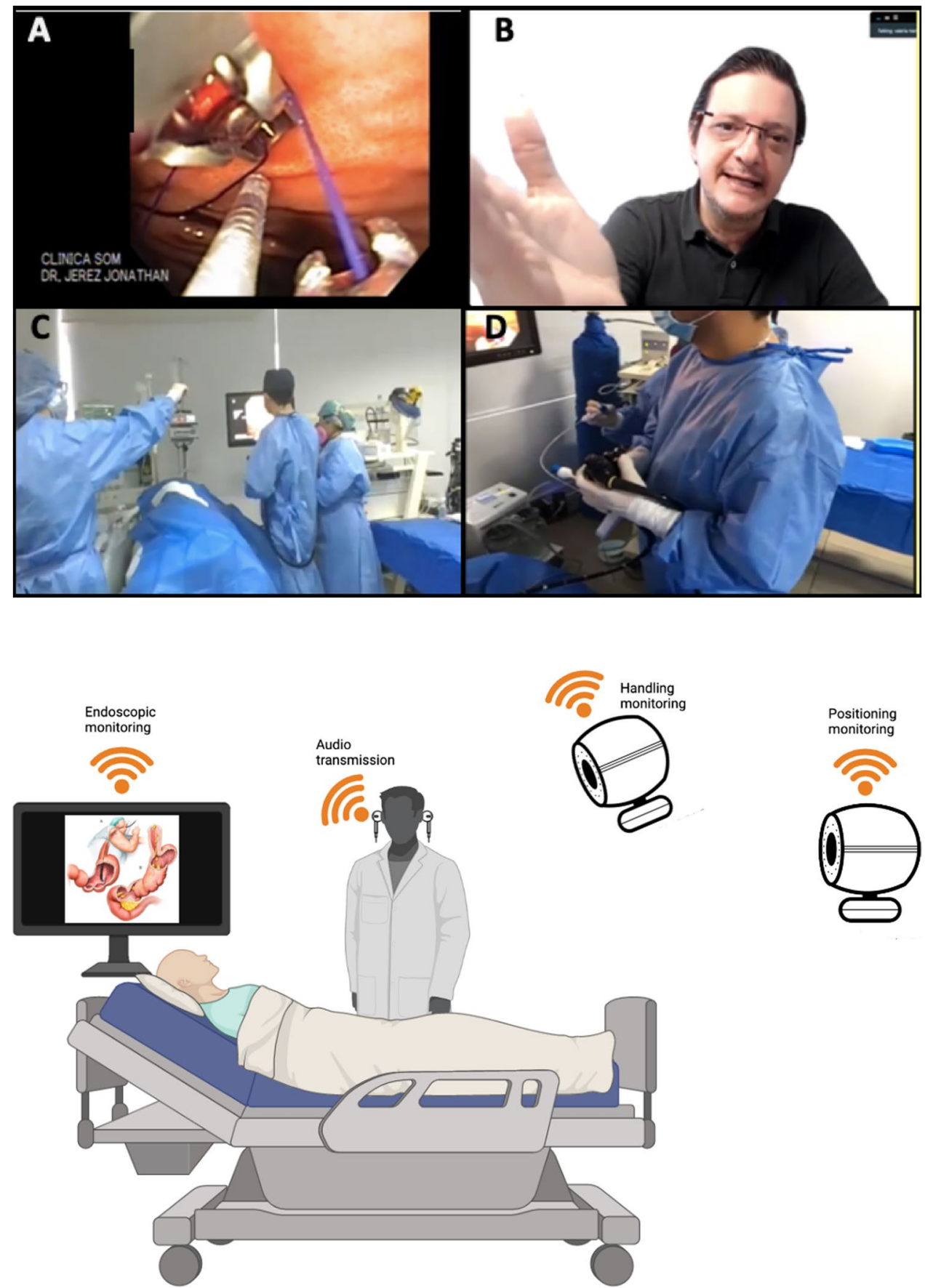

Fig. 7 Schematics for room setup

restrictions, and a local proctor was not available since this was a novel procedure in the country. This endoscopic procedure followed international standards, previously described as in the Brazilian Consensus on Endoscopic Sleeve Gastroplasty and other reports. The endoscopic procedure time and suturing time decreased over time, proving refinement of surgical skills, whereas the effect size of the change was large for both assessments.

Learning curve model has become a widely employed tool in medicine and surgery training process [16]. It visually describes the learner's performance improvement over time during acquisition of new skills. Measuring the learning curve of surgical procedures has important implications for surgical innovation, education, and patient safety [17].

In the present study, mean duration of the endoscopic procedure was $106.4 \mathrm{~min}$. The trainee experienced significant reductions in overall operative time during the first 10 cases $(p \leq 0.05)$.

A study that included 21 consecutive patients reported that the length of procedure decreased significantly 
across consecutive procedures, with a learning plateau at $101.5 \mathrm{~min}$ vary similar to the results we achieved [17]. The variation of median and mean procedure times in the current literature ranges from 75 to $157 \mathrm{~min}$, in series of 20 and 10 patients which is consistent with results of the current report [18]. There are differences in learning curves between the learning curve of only 1 trainee and when there are a variety of surgeons because each person generally starts at different levels; our results are very similar to those reported by Hill et al. [19]. Another study reported learning curves with only one trainee [20].

The global pandemic of COVID-19 has led to the suspension of in-person teaching activities in many countries, including Ecuador. However, it also fostered the development innovative solutions, in both clinical and educational settings, that may become fundamental in future teaching models, despite resolution of the pandemic [21].

Medical education and training programs have been affected by social distancing. More than 900 million learners in all levels of education, including higher education, felt the impact of the pandemic in their learning process during 2020 [19]. As a result, medical students have moved away from bedside training to alternative online resources such as virtual learning, videoconferencing, social media, and telemedicine [18, 20, 22, 23].

Medical teleproctoring plays a dual role as it educates and provides medical care simultaneously. Systematic reviews have already compared surgical teleproctoring to on-site training. There were comparable safety and efficacy profiles between the two models [24]. Our study suggests that it may also be applied to advanced endoscopic procedures.

There are some limitations in our report. First, the analysis presents a short learning curve of a single endoscopic center. Nonetheless, it was enough to demonstrate a significant improvement in performance, which supports the efficacy of the proposed learning model. Moreover, our analysis did not include long-term results after the surgical procedure, but that was not the aim of this study.

To our knowledge, our study is the first to demonstrate the feasibility of learning ESG using the teleproctoring approach and its learning curve. There are some studies dealing with virtual environments for learning but in other surgical situations [25-28]. This is also the first time that Ecuador and Brazil develop a strategy to proctor safely and effectively through telemedicine. The success with surgical techniques motivated great interest among other specialists. The cases reported in the current study demonstrate that this kind of surgical procedure may be employed as an effective learning method.

Learning curves could be better when there is already a systematization of the technique and when the experience of the trainee is bigger. The practice of the surgical technique in this case always included feedback with comments from the advanced instructor or proctor.

After completing this training program, the trainee has increased his capacity to perform more than 50 cases of this kind of surgery without complications or serious adverse events, The use of all the learnings acquired during these sessions with the proctor allowed this result.

\section{Conclusions}

The training program was effective and provided a shortened pathway to gaining autonomous proficiency through a unique learning methodology. Despite the resolution of the COVID-19 pandemic, part of the innovations from this difficult moment will certainly compose the standard-of-learning for future generations.

\section{Declarations}

Ethics All procedures performed in studies involving human participants were in accordance with the ethical standards of the institutional and/or national research committee and with the 1964 Helsinki declaration and its later amendments or comparable ethical standards. All patients involved in this study signed a written consent to undergo the proposed procedure.

Consents Informed consent was obtained from all individual participants included in the study. Additional informed consent was obtained from all individual participants for whom identifying information is included in this article.

Conflics of interest Manoel Galvao Neto 1 reports receiving personal fees for lectures from Erbe Elektromedizin $\mathrm{GmbH}$; he is consultant for GI Dynamics, Apollo EndoSurgery, USGI, Colubris Mx, Scitech, and MITech; is Scientific Advisor for Apollo EndoSurgery and Keyron; he is speaker for Olympus LA, Erbe, and Medtronic LA. Barham Aby Dayyeh is a consultant for Boston Scientific, Medtronic, BFKW, Endogenex, Hemostasis, Spatz Medical, Endo-TAGSS Metamodix. He is the recipient of research support from Apollo Endosurgery, USGI medical, Boston Scientific, Medtronic, Endogastric Solutions, Spatz Medical, Aspire Bariatric; he is a speaker for Olympus and Johnson and Johnson. All other authors disclose no potential conflicts of interest.

\section{References}

1. Brunaldi VO, Galvao Neto M. Gastric space-occupying devices for management of obesity and metabolic disease. Techniques and Innovations in Gastrointestinal Endoscopy [Internet]. Elsevier; 2020;22:130-5 https://doi.org/10.1016/j.tige.2020.05.001

2. Brunaldi VO, Galvao NM. Endoscopic techniques for weight loss and treating metabolic syndrome. Curr Opin Gastroentero. 2019;35:424-31.

3. Alqahtani A, Al-Darwish A, Mahmoud AE, Alqahtani YA, Elahmedi M. Short-term outcomes of endoscopic sleeve gastroplasty in 1000 consecutive patients. Gastrointestinal endoscopy. United States; 2018; 
4. de Moura DTH, de Moura EGH, Thompson CC. Endoscopic sleeve gastroplasty: From whence we came and where we are going. World journal of gastrointestinal endoscopy. 2019 322-8.

5. Erridge S, Yeung DKT, Patel HRH, Purkayastha S. Telementoring of Surgeons: A Systematic Review. Surg Innov. 2019;26:95-111.

6. McCullough MC, Kulber L, Sammons P, Santos P, Kulber DA. Google glass for remote surgical tele-proctoring in low- and middle-income countries: A feasibility study from Mozambique. Plast Reconstr Surg Glob Open. 2018;6:e1999.

7. Hopper AN, Jamison MH, Lewis WG. Learning curves in surgical practice. Postgrad Med J. 2007;83:777-9.

8. Galvao-Neto MDP, Grecco E, de Souza TF, de Quadros LG, Silva LB, Campos JM. Endoscopic sleeve gastroplasty - minimally invasive therapy for primary obesity treatment. Arq Bras Cir Dig. 2016;29(Suppl 1):95-7.

9. Neto MG, Silva LB, de Quadros LG, Grecco E, Filho AC, de Amorim AMB, et al. Brazilian consensus on endoscopic sleeve gastroplasty. Obes Surg. 2021;31:70-8.

10. Feldman LS, Cao J, Andalib A, Fraser S, Fried GM. A method to characterize the learning curve for performance of a fundamental laparoscopic simulator task: defining "learning plateau" and "learning rate." Surgery. 2009;146:381-6.

11. Singh S, Sharma V, Patel P, Anuragi G, Sharma RG. Telementoring: an Overview and Our Preliminary Experience in the Setting Up of a Cost-effective Telementoring Facility. Indian J Surg. 2016;78:70-3.

12. Datta N, MacQueen IT, Schroeder AD, Wilson JJ, Espinoza JC, Wagner JP, et al. Wearable Technology for Global Surgical Teleproctoring. J Surg Educ. 2015;72:1290-5.

13. Nakhla J, Kobets A, De la Garza RR, Haranhalli N, Gelfand Y, Ammar A, et al. Use of Google Glass to Enhance Surgical Education of Neurosurgery Residents: "Proof-of-Concept" Study. World Neurosurg. 2017;98:711-4.

14. Duftschmid G, Binder M, Wrba T, Dorda W, Pehamberger H. Guidelines for the planning and implementation of telemedical applications. Wien Klin Wochenschr. 2005;117:673-83.

15. Jumreornvong O, Yang E, Race J, Appel J. Telemedicine and Medical Education in the Age of COVID-19. Acad Med. 2020;95:1838-43.

16. Khan N, Abboudi H, Khan MS, Dasgupta P, Ahmed K. Measuring the surgical "learning curve": methods, variables and competency. BJU Int. 2014;113:504-8.
17. Arora KS, Khan N, Abboudi H, Khan MS, Dasgupta P, Ahmed $\mathrm{K}$. Learning curves for cardiothoracic and vascular surgical procedures-a systematic review. Postgrad Med. 2015;127:202-14.

18. Dedeilia A, Sotiropoulos MG, Hanrahan JG, Janga D, Dedeilias P, Sideris M. Medical and Surgical Education Challenges and Innovations in the COVID-19 Era: A Systematic Review. In vivo. 2020;34:1603-11.

19. Nicola M, Alsafi Z, Sohrabi C, Kerwan A, Al-Jabir A, Iosifidis $\mathrm{C}$, et al. The socio-economic implications of the coronavirus pandemic (COVID-19): A review. Int J Surg. 2020;78:185-93.

20. Rose S. Medical Student Education in the Time of COVID-19. JAMA. 2020;323:2131-2.

21. Thomsen ASS, Saleh GM. Telementoring and remote training in the present era. Acta ophthalmologica. 2020;

22. Sahi PK, Mishra D, Singh T. Medical Education Amid the COVID-19 Pandemic. Indian Pediatr. 2020;57:652-7.

23. Singh K, Srivastav S, Bhardwaj A, Dixit A, Misra S. Medical Education During the COVID-19 Pandemic: A Single Institution Experience. Indian Pediatr. 2020;57:678-9.

24. Bilgic E, Turkdogan S, Watanabe Y, Madani A, Landry T, Lavigne D, et al. Effectiveness of Telementoring in Surgery Compared With On-site Mentoring: A Systematic Review. Surg Innov. 2017;24:379-85.

25. Talbot M, Harvey EJ, Berry GK, Reindl R, Tien H, Stinner DJ, et al. A pilot study of surgical telementoring for leg fasciotomy. J R Army Med Corps. 2018;164:83-6.

26. Schlachta CM, Sorsdahl AK, Lefebvre KL, McCune ML, Jayaraman S. A model for longitudinal mentoring and telementoring of laparoscopic colon surgery. Surg Endosc. 2009;23:1634-8.

27. Treter S, Perrier N, Sosa JA, Roman S. Telementoring: a multiinstitutional experience with the introduction of a novel surgical approach for adrenalectomy. Ann Surg Oncol. 2013;20:2754-8.

28. Ladd BM, Tackla RD, Gupte A, Darrow D, Sorenson J, Zuccarello $\mathrm{M}$, et al. Feasibility of Telementoring for Microneurosurgical Procedures Using a Microscope: A Proof-of-Concept Study. World Neurosurg. 2017;99:680-6.

Publisher's Note Springer Nature remains neutral with regard to jurisdictional claims in published maps and institutional affiliations. 